International Journal of Medical Arts 2020; 2 [2]: 358-364.

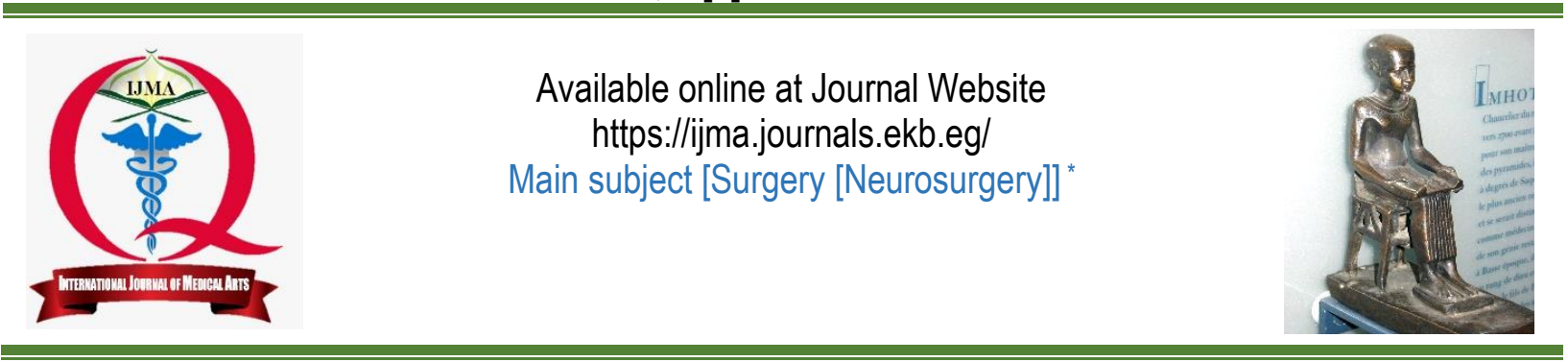

Original article

\title{
Outcome of transpedicular screw fixation with Posterior Interbody Fusion in Management of Spondylolysthesis
}

Abd Elhalim Abd -Alrazik Moussa; Mohamed Shaban Ali; Mohamed Galal

Department of Neurosurgery, Damietta Faculty of Medicine, Al-Azhar University, Egyp.

Corresponding author: Mohamed Galal

Email: mgalalneuros@gmail.com

Received at: December 13, 2019; Revised at: April 15, 2020; Accepted at: April 16, 2020; Available online at: April 16, 2020

DOI: 10.21608/ijma.2020.20954.1054

\section{ABSTRACT}

Background: Spondylolysthesis represents a particular and relatively frequent mechanism of intervertebral instability. It could cause low back pain due to forward or anterior displacement of one vertebra in relation the adjacent lower vertebra. There are many treatment interventions. However, there was no consensus on the ideal approach.

Aim of the work: To assess the outcome of trans-pedicular screw fixation with posterior inter-body fusion in management of lumber and lumbosacral spondylolysthesis.

Patients and Methods: This is a prospective study, included twenty patients who underwent surgical lumbar laminectomy and disc removal with lumbar pedicle screw fixation with inter body fusion for patients with Spondylolysthesis who failed conservative measures.

Results: The mean preoperative visual analogue score (VAS) for pain was $7.75 \pm 0.72$ that decreased to $1.35 \pm$ 0.59 at the end of postoperative sixth month, with statistically significant decrease. In addition, the majority of cases had no significant complications, although complication rate was $25 \%$.

Conclusion: Posterolateral fusion with pedicle Screws fixation minimizes dislocation, achieves adequate decompression, corrects the sagittal axis, and accomplishes fusion. We successfully achieved solid fusion with good mechanical alignment in majority of the patients.

Keywords: Spondylolysthesis; Pedicle screw; Posterolateral fusion; transpedicular; Fixation.

This is an open access article under the Creative Commons license [CC BY] [https://creativecommons.org/licenses/by/2.0/]

Please cite this article as: Moussa AA, Ali MS, Galal M. Outcome of transpedicular screw fixation with Posterior Interbody Fusion in Management of Spondylolysthesis. IJMA 2020; 2[2]: 358-364.

* Main subject and any subcategories have been classified according to researchers' main field of study. 


\section{INTRODUCTION}

Spondylolysthesis refer to forward displacement of a vertebra over the underlying one. It could be congenital, isthmic, degenerative, traumatic, pathologic or postoperative ${ }^{[1]}$,

The most commonly affected levels are L4-L5 $(73.0 \%)$ followed by L3-L4 (18.0\%). Spondylolysthesis affects $2.7 \%-5.0 \%$ of adult males and $8.1 \%-10.0 \%$ of adult females, and about $5 \%$ with L5$\mathrm{S} 1$ as the commonest affected level in pediatrics ${ }^{[2]}$.

There were five grades of slippage expressed as a percentage of the width of the slipped vertebral body $(0-25 \%, 25-50 \%, 50-75 \%, 75-100 \%$ and more than $100.0 \%$ for grades I, II, III, IV and V successively) ${ }^{[3]}$.

The typical presentation of spondylolysthesis is low back pain with or without neurologic and/or radicular manifestations ${ }^{[4]}$.

The diagnostic workup usually included anteroposterior (AP) and lateral imaging films, with flexion/extension films as a key components in diagnostic workup and magnetic resonance imaging (MRI) (T-weighted sagittal and axial views) represent the gold-standard that could elucidate any compression on neuro-logical components[5].

Treatment usually determined by the severity of symptoms. Mild cases treated by non-surgical measures (rest, non-steroidal anti-inflammatory, physical therapy, and modifications of life style). Surgical intervention indicated with conservative therapy failed, for patients with neurological affection, progressed pain leading to limitation of daily activities[6,7].

Surgical options comprise de-compression, arthrodesis and circumferential fusion. Circumferential fusion hypothetically can relief the compression on the disc space, increase rate of fusion and improve correction of the deformity. Circumferential fusion could be achieved by anterior, posterior or transforaminal lumbar interbody fusion $[6,8]$,

Paradoxically, despite this high rate of Spondylolysthesis and availability of different medical and surgical treatment options, there is no strong consensus on treatment, regarding medical, surgical or choice between medical and surgical options ${ }^{[9]}$.

\section{AIM OF THE WORK}

The aim of this study is to assess the outcome of transpedicular screw fixation with posterior interbody fusion in management of lumber and lumbosacral Spondylolysthesis.

\section{PATIENTS AND METHODS}

This study is a prospective study carried out on twenty patients who underwent surgical lumbar laminectomy and disc removal with lumbar pedicle screw fixation with inter body fusion for patients with Spondylolysthesis who failed conservative measures.

The inclusion criteria were: 1) Failure of conservative treatment for 6 months; 2) Spondylolysthesis between grade I and II; 3) Patients with isthmic or degenerative Spondylolysthesis.

However, exclusion criteria were: 1) Patients with severe Spondylolysthesis grade IV; 2) Patients with associated scoliosis; and 3) Acute traumatic Spondylolysthesis.

Preoperatively, the work of assessment included history taking, neurological examination and calculation of Oswestry Disability Index (ODI)[10], Visual Analogue Score (VAS) $)^{[11]}$ for pain assessment, walking distance and Japanese Orthopedic Association (JOA) score[12] for low back pain.

In addition, imaging studies included MRI, computed tomography (CT) and dynamic plain Xray.

The surgical treatment was carried out under general anesthesia with preoperative antibiotic prophylaxis in a prone position on spinal frame, with the abdomen free and the spine flexed to open the inter-laminar spaces. The surgical technique continues as described by Periasamy et al. ${ }^{[13]}$

The operative data included the affected site, the intraoperative blood loss, operative time and mode of fixation used. Postoperatively, there was assessment of pain and neurological disability if present. In addition, any intraoperative or postoperative complications were documented.

In this study we followed patients immediate postoperative, one week after surgery and six months postoperative where we evaluated them by clinical and radiological means. 
Ethical considerations: Lumber laminectomy and disc removal with lumbar pedicle screw fixation with inter body fusion consent includes discussing the operative procedure with the patient with its intended benefits of pain relief and possible improving function and symptoms of walk.

Discussing neurological deterioration, complications such as (Dural tear, infection, hematoma, nerve root injury).

The patient confidentiality and his/her right for withdrawal at any time was assured. The study protocol was approved by the local institutional review board (IRP) of Al-Azhar Faculty of Medicine.

Statistical analysis: Data entry and analyses were performed using SPSS statistical package version 10 (SPSS, Inc., Chicago, IL, USA). The quantitative data were presented as a mean and standard deviation.

Paired t-test was conducted to evaluate the impact of surgery on the mean of outcome scores. The qualitative data were presented as number and percentage. The chi-square $\left(X^{2}\right)$ was used to find the association between variables of qualitative data. $P$ value of $\leq 0.05$ indicate significant difference.

\section{RESULTS}

The present trial included 20 subjects with various degrees of Spondylolysthesis; 13 of them $(65.0 \%)$ were females indicating female sex predominance; their age ranged from 29 to 59 years, and $50.0 \%$ of them were in the age group (40-50 years).

Clinically, the majority of cases $(80 \%)$ presented by low back pain with left sciatica $(80.0 \%)$, back pain and right sciatica $(10 \%)$, back pain, right sciatica and right food drop (5.0\%) and weakness in flexion of left hip and paresthesia in left inguinal region (5.0\%).

The most affected level was L4-L5 (encountered in $70.0 \%)$ followed by L5-S1 $(25.0 \%)$ and finally L3L4 (5.0\%) (Table 1). All patients underwent pre-and post-operative $x$-ray and computed tomography.

In the present work, intraoperative blood loss ranged from 400 to $700 \mathrm{ml}$; the mean values was $510.0 \mathrm{ml}$; the operative time ranged from 3 to 3.5 hours; the mean operative time was 3.20 hours; the type of fusion was pedicle screw fixation plus posterior lumber interbody fusion among 18 subjects $(90 \%)$ and with transforaminal lumber interbody fusion among 2 subjects (10.0\%).

Complications were reported in 5 subjects (25.0\%); of those, CSF lead was reported in 2 subjects, represented $40 \%$ of all complications, maldirected screw, slippage of the case, and secondary myelomeningiocele (each in one case) (Table 2).

In the present study, preoperative pain ranged from 7 to 9 , and the mean value was $7.75 \pm 0.72$, which significantly decreased to $2.70 \pm 0.80$ at one week postoperative and significantly decreased to $1.35 \pm 0.59$ at six months postoperatively.

In addition, there was significant decrease at six months postoperatively when compared to values at the first postoperative week (Table 3).

There was no statistically significant difference between studied patients regarding muscle weakness (there was 2 patients with muscle weakness, and at the postoperative time, the same patients still had muscle weakness. However, the degree of weakness decreased).

Figures 1 to 6 represented pre- and postoperative images for a 50 years old female patient with history of back pain and left sciatica with failure of conservative measures more than 6 months. Preoperative $\mathrm{x}$-rays and MRI were done showing L4-L5 Spondylolysthesis.

The patient underwent laminectomy of $L 4$ and $L 5$ and discectomy of $L 4-5$, pedicle screw fixation between L4-L5 and interbody fusion by a cage. The operation was done by PLIF approach. The patient improved clinically as determined by JOA, ODI and VAS for back and leg pain. Post-operative x-rays of lumber spine was done showing rods and screws and cage in the proper site with no post-operative instability. 
Table (1): Patient characteristics

\begin{tabular}{|c|c|c|}
\hline \multirow{3}{*}{ Sex } & & Statistics \\
\hline & Male & $7(35.0 \%)$ \\
\hline & Female & $13(65.0 \%)$ \\
\hline \multirow{4}{*}{ Age } & Mean $\pm S D ;$ Minimum-Maximum & $46.85 \pm 8.45 ; 29-59$ \\
\hline & $<40 y$ & $4(20.0 \%)$ \\
\hline & $40-50 y$ & $10(50.0 \%)$ \\
\hline & $>50 y$ & $6(30.0 \%)$ \\
\hline \multirow{4}{*}{$\begin{array}{c}\text { Clinical } \\
\text { examination }\end{array}$} & Back pain and left sciatica & $16(80.0 \%)$ \\
\hline & Back pain and right sciatica & $2(10.0 \%)$ \\
\hline & Back pain, right sciatica and right foot drop & $1(5.0 \%)$ \\
\hline & Weakness in flexion of left hip and paresthesia in left inguinal region & $1(5.0 \%)$ \\
\hline \multirow{3}{*}{$\begin{array}{l}\text { Affected } \\
\text { level }\end{array}$} & L3-L4 & $1(5.0 \%)$ \\
\hline & L4-L5 & $14(70.0 \%)$ \\
\hline & L5-S1 & $5(25.0 \%)$ \\
\hline
\end{tabular}

Table (2): Intraoperative data and postoperative complications

\begin{tabular}{|c|c|c|}
\hline \multirow{2}{*}{\multicolumn{2}{|c|}{ Blood loss (ml) }} & Statistics \\
\hline & & $510.0 \pm 83.67 ; 400-700$ \\
\hline \multicolumn{2}{|c|}{ Operative time (hours) } & $3.20 \pm 0.25 ; 3-3.5$ \\
\hline \multirow[t]{2}{*}{ Type of fusion } & Pedicle screw plus PLIF & $18(90.0 \%)$ \\
\hline & Pedicle screw plus TLIF & $2(10.0 \%)$ \\
\hline \multirow[t]{6}{*}{ Complications } & No & $15(75.0 \%)$ \\
\hline & Yes & $5(25.0 \%)$ \\
\hline & C.S.F leak & $2(40.0 \%)$ \\
\hline & Mal-directed screw & $1(20.0 \%)$ \\
\hline & Slippage of the cage & $1(20.0 \%)$ \\
\hline & Secondary myelomeningiocele & $1(20.0 \%)$ \\
\hline
\end{tabular}

Table (3): Comparison between pre-operative pain and post-operative in one week and six months

\begin{tabular}{|c|l|c|c|c|c|c|c|}
\hline & Preoperative & $\begin{array}{c}\text { One week } \\
\text { postoperative }\end{array}$ & $\begin{array}{c}\text { Six months } \\
\text { postoperative }\end{array}$ & P1 & P2 & P3 \\
\hline \multirow{2}{*}{ VAS } & Mean & $7.75 \pm 0.72$ & $2.70 \pm 0.80$ & $1.35 \pm 0.59$ & 0.001 & $<0.001$ & 0.004 \\
\cline { 2 - 8 } & Min.-Max. & $7-9$ & $2-4$ & $1-3$ & & & \\
\hline
\end{tabular}

$p_{1}: p$ value for comparing between Preoperative and postoperative one week; $p_{2}: p$ value for comparing between Preoperative and post six months; $p_{3}: p$ value for comparing between postoperative one week and six months
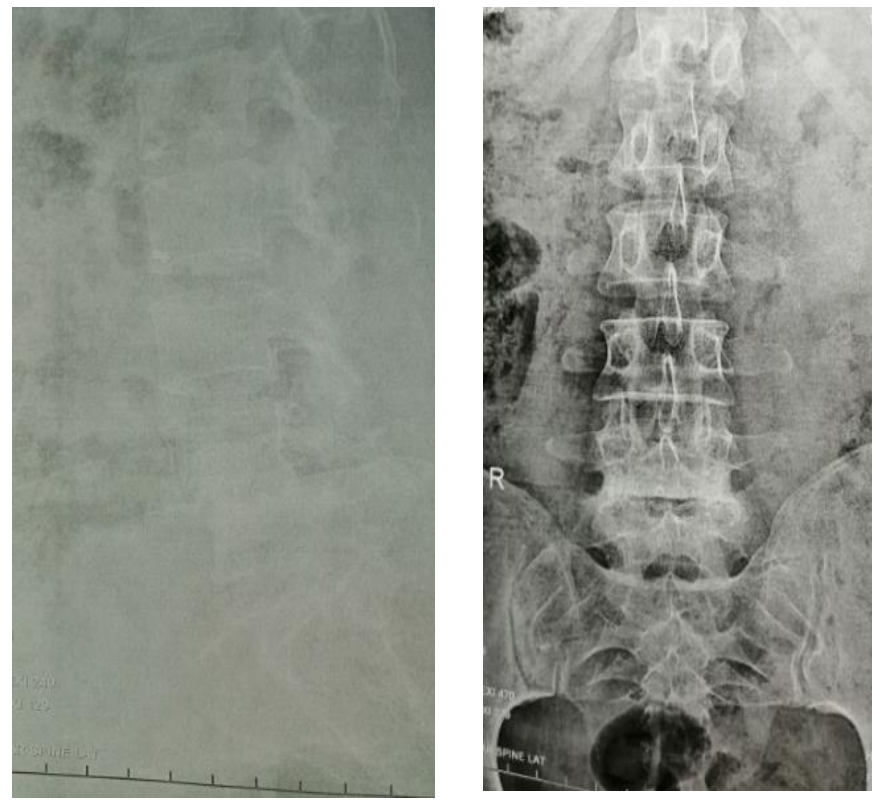

Figure (1): Pre-operative $x$ rays of lumbar spine showing L4-L5 Spondylolysthesis

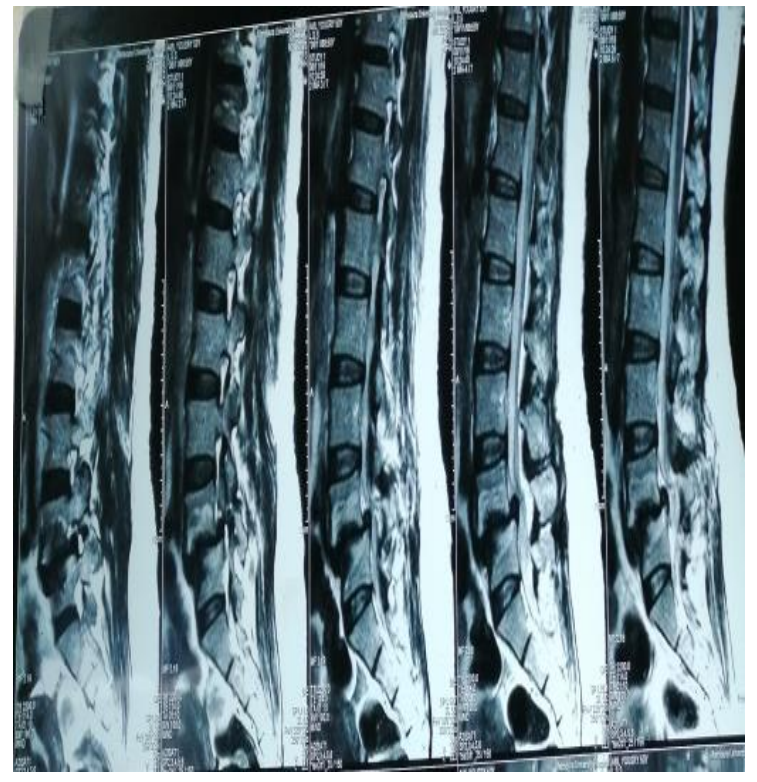

Figure (2): Pre-operative MRI of lumbar spine showing L4L5 Spondylolysthesis 

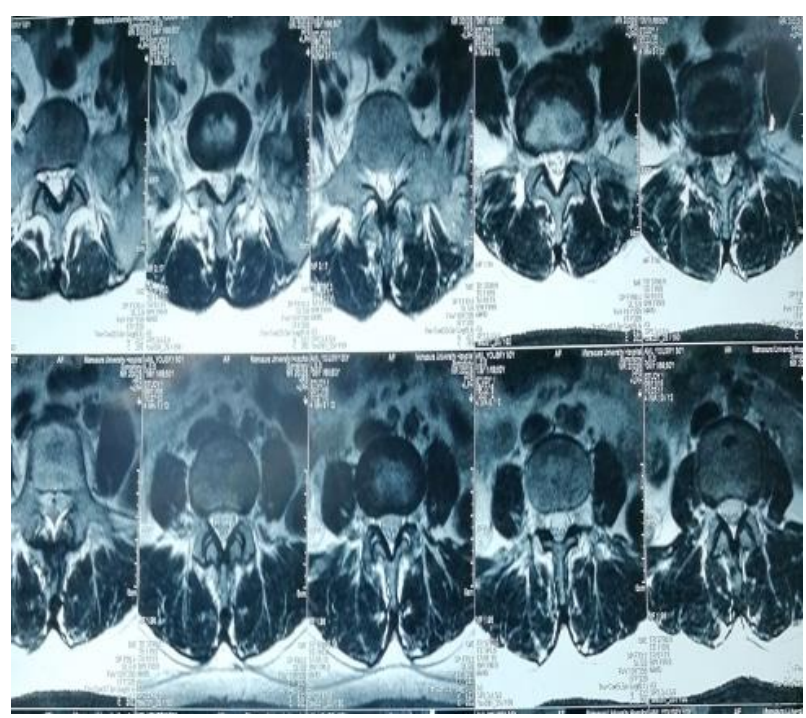

Figure (3): Pre-operative MRI of lumbar spine showing L4-L5 Spondylolysthesis
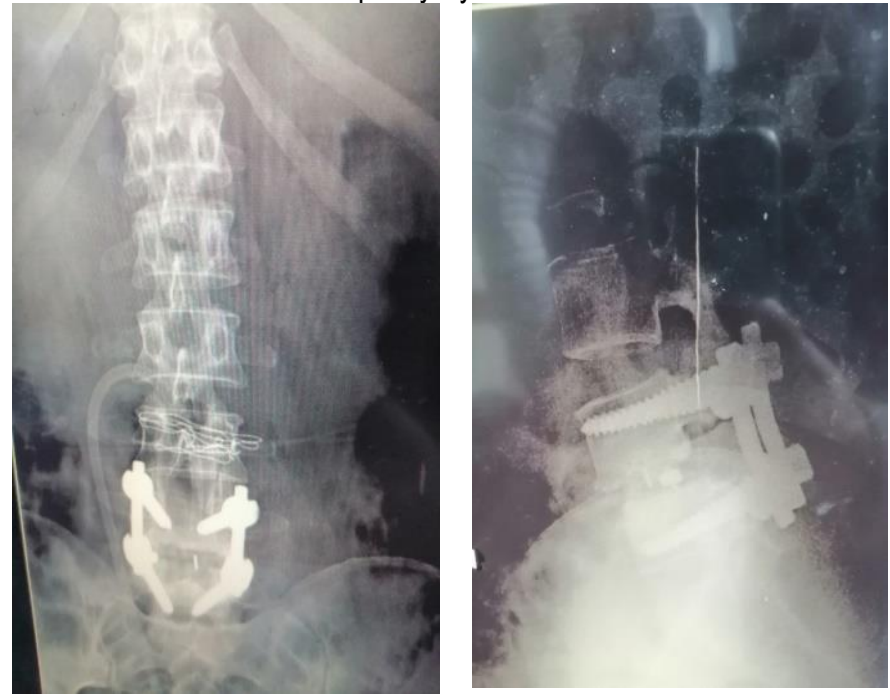

Figure (5): Post-operative $x$ rays of lumbar spine showing pedicle screws of 14 and 15 with PLIF

\section{DISCUSSION}

Results of the present study revealed female sex predominance, and the majority were females.

Benguluri[14] conducted a study on 86 patients (58 females and 28 males), with the average age of 43 years.

In addition, Madan and Boeree[15] reported a mean age of 44.4 years, while $\mathrm{Kim}$ and Kim[16] included patients with mean age of 41.3 years.

Results of the present work are going in agreement with Agabegi and Fischgrund[17] who reported that, Spondylolysthesis in their work was either of isthmic or degenerative types with radicular manifestations and low back pain as the main symptoms.

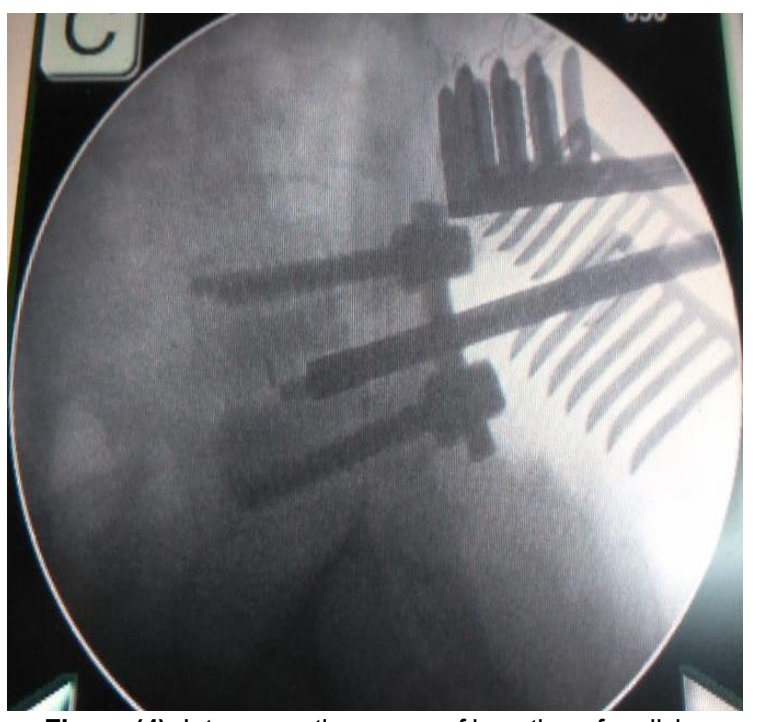

Figure (4): Intra-operative $x$ rays of insertion of pedicle screws of 14 and 15 with PLIF

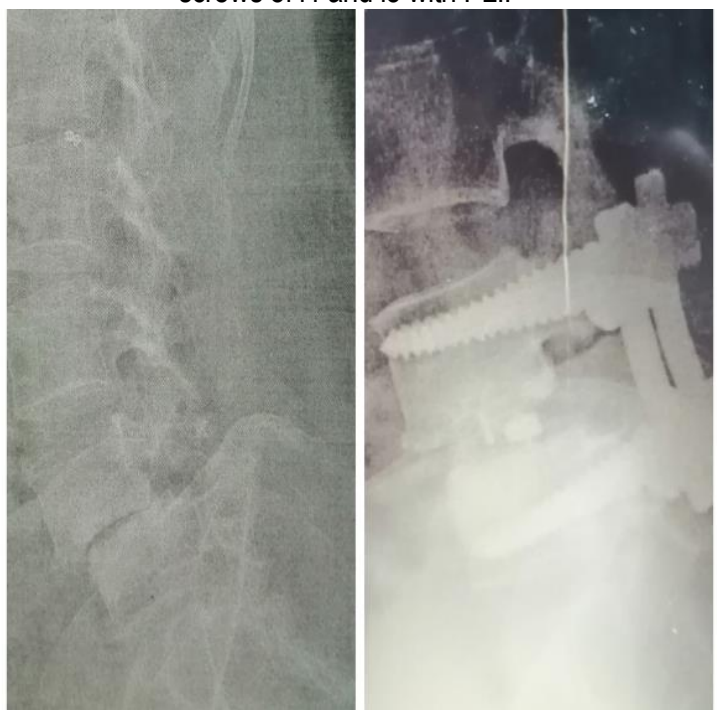

Figure (6): Comparison between pre- and post-operative Spondylolysthesis $L 4-5$

Furthermore, results of present work agree with Benguluri [14] who reported that, the most common affected level was L4-L5 (55 cases) followed by L5S1 (31 patients).

On the other side, Dantas et al. ${ }^{[18]}$ reported equal number $(45 \%)$ of patients involving the L4-L5 and L5S1 levels. Otherwise, Ganju et al.[19] reported the L5-S1 affected rate of $52.27 \%$ and L4-L5 of $47.72 \%$.

The current study revealed VAS score decreased from $7.75 \pm 0.72$ preoperatively to $1.35 \pm 0.59$ at six months with statistical significant decrease. These results agree with Rezk et al.[20] and El-Sayed et al.[21] who reported significant improvement of pain after surgical intervention for Spondylolysthesis.

Hackenberg et al.[22] reported that pain 
improvement as reflected by VAS was related to the pre-operative pathology, where the isthmic Spondylolysthesis had more VAS improvement when compared to the degenerative type.

The present study assessed complication rates among studied groups revealing that majority of studied groups (75\%) had no complications, 2 cases had C.S.F leak. Rezk et al.[20] yielded a complication rate of $17.1 \%$. CSF leaks could occur as a consequence of spine trauma or surgical intervention. These leaks are a significant problem as they are associated with persistent headaches and liable to infection (e.g., meningitis). Surgical reintervention is often required and thorough direct closure of the dura is required. Otherwise, fascial graft for closure become mandatory [23].

In conclusion, the described surgical intervention yielded lower postoperative comorbidities. Posterolateral fusion with pedicle screw fixation was associated with minimal dislocation, achieves acceptable decompression, fixes the sagittal axis, and attains satisfactory fusion. Solid fusion with good mechanical alignment was attainable in the majority of patients. Posterolateral fusion can be an alternative for the treatment of lumbar Spondylolysthesis.

\section{Financial and Non-financial Relationships and Activities of Interest}

None

\section{REFERENCES}

1. Majid K, Fischgrund JS. Degenerative lumbar Spondylolysthesis: trends in management. J Am Acad Orthop Surg 2008; 16:208-215. [DOI: 10.5435/00124635-200804000-00004].

2. Jacobsen S, Sonne-Holm S, Rovsing H, Monrad H, Gebuhr P. Degenerative lumbar Spondylolysthesis: an epidemiological perspective: the Copenhagen Osteoarthritis Study. Spine 2007;32(1):120-125. [DOI: 10.1097/ 01. brs. 0000250979.12398.96].

3. Mostofi K, Gharaie Moghaddam B, Karimi Khouzan R, Daryabin $\mathbf{M}$. The reliability of LERI's sign in L4 and L3 radiculalgia. J Clin Neurosci. 2018:50:102 - 104. [DOI: 10.1016/j.jocn.2018.01.025].

4. Kalichman L, Kim DH, Li L, Guermazi A, Berkin V, Hunter DJ. Spondylolysis and Spondylolysthesis: prevalence and association with low back pain in the adult community-based population. Spine (Phila Pa 1976) 2009; 34:199-205. [DOl: 10.1097/BRS.0b013e31818edcfd].
5. Solomou A,Kraniotis P,Rigopoulou A, Petsas T. Frequent Benign, Nontraumatic, Noninflammatory Causes of Low Back Pain in Adolescents: MRI Findings. Radiol Res Pract. 2018; 2018:7638505. [DOl:10.1155/ 2018/7638505].

6. Jones TR, Rao RD. Adult isthmic Spondylolysthesis. J Am Acad Orthop Surg 2009; 17 (10):609-617. [DOI: 10.5435/00124635-200910000-00003].

7. Abi-Hanna D, Kerferd J, Phan K, Rao P, Mobbs R. Lumbar Disk Arthroplasty for Degenerative Disk Disease: Literature Review. World Neurosurg. 2018; 109: 188196. [DOI: 10.1016/ j.wneu.2017.09.153].

8. Kwon BK, Hilibrand AS, Malloy K, Savas PE, Silva MT, Albert TJ, Vaccaro AR. A critical analysis of the literature regarding surgical approach and outcome for adult low-grade isthmic Spondylolysthesis. J Spinal Disord Tech. 2005; 18(Suppl): S30-S40. [DOI: 10.1097/01.bsd. 0000133064.20466.88].

9. Guigui P, Ferrero E. Surgical treatment of degenerative Spondylolysthesis. Orthop Traumatol Surg Res. 2017; 103(1S):S11-S20. [DOI: 10.1016/j.otsr.2016.06.022].

10. Vanti C, Ferrari S, Villafañe JH, Berjano P, Monticone M. Responsiveness and minimum important change of the Oswestry Disability Index in Italian subjects with symptomatic lumbar Spondylolysthesis. J Orthop Traumatol. 2017 Jun; 18(2): 145-150. [DOl: 10.1007/s10195-017-0446-y].

11. Nava-Bringas TI, Hernández-López M, Ramírez-Mora I, Coronado-Zarco $\mathrm{R}$, Israel Macías-Hernández $\mathrm{S}$, Cruz-Medina E, Arellano-Hernández A, LeónHernández SR. Effects of a stabilization exercise program in functionality and pain in patients with degenerative Spondylolysthesis. J Back Musculoskelet Rehabil. 2014; 27 (1): 41-6. [DOI: 10.3233/BMR130417].

12. Song D, Song D, Zhang K, Chen Z, Wang F, Xuan T. Double-level isthmic Spondylolysthesis treated with posterior lumbar interbody fusion: A review of 32 cases. Clin Neurol Neurosurg. 2017; 161:35-40. [DOI: 10.1016/ j. clineuro. 2017.08.007.]

13. Periasamy K, Shah K, Wheelwright EF. Posterior lumbar interbody fusion using cages, combined with instrumented posterolateral fusion: a study of 75 cases. Acta Orthop Belg. 2008; 74(2):240-8. [PMID: 18564483].

14. Benguluri R, Kumar CS. Surgical Management of Spondylolysthesis by Pedicular Screw Rod System and Postero-Lateral fusion. IOSRJDMS 2018; 17 (4): 61 70. [DOI: 10.9790/0853-1704056170].

15. Madan S, Boeree NR. Outcome of posterior lumbar interbody fusion versus posterolateral fusion for spondylolytic Spondylolysthesis. Spine (Phila Pa 1976) 2002; 27:1536-1542. [DOI: 10.1097/00007632200207150-00011].

16. Kim EH, Kim HT. En bloc partial laminectomy and posterior 
lumbar interbody fusion in foraminal spinal stenosis. Asian Spine J. 2009; 3: 66-72. [DOI: 10.4184/ asj. 2009.3.2.66].

17. Agabegi SS, Fischgrund JS. Contemporary management of isthmic Spondylolysthesis: pediatric and adult. Spine J. 2010; 10:530-43. [DOI: 10.1016/j.spinee. 2010.02.023].

18. Dantas FL, Prandini MN, Ferreira MA. Comparison between Posterior Lumbar Fusion with Pedicle Screws and Posterior Lumbar Interbody Fusion with Pedicle Screws in Adult Spondylolysthesis. Arquivos De NeuroPsiquiatria 2007; 65:764-770. [DOI: 10.1590/s0004282x2007000500006].

19. Ganju A. Isthmic Spondylolysthesis. Neurosurgical Focus 2002; 13: E1. [DOI: 10.3171/ foc.2002.13.1.2].

20. Rezk EMA, Elkholy AR, Shamhoot EA. Transforaminal lumbar interbody fusion (TLIF) versus posterior lumbar interbody fusion (PLIF) in the treatment of single-level lumbar Spondylolysthesis. Egypt J Neurosurg 2019; 34 (26): 6 pages [DOI: 10.1186/ s41984-019-0052-9].
21. El-Sayed AA, El-Qazaz MY, Mohamed KE, Shater MS. Evaluation of transforaminal lumbar interbody fusion versus posterior lumbar interbody fusion in patients of lumbar instability submitted to transpedicular screws fixation. Med J Cairo Univ. 2012; 80(1):185-192.

22. Hackenberg L, Halm H, Bullmann V, Vieth V, Schneider M, Liljenqvist $U$. Transforaminal lumbar interbody fusion: a safe technique with satisfactory three to five years results. Eur Spine J. 2005; 14:551-8. [DOI: 10.1007/s00586-004-0830-1].

23. Poussa M, Schlenzka D, Seitsalo S, Ylikoski M, Hurri H, Osterman K. Surgical Treatment of Severe Isthmic Spondylolysthesis In Adolescents. Reduction or Fusion in Situ. Spine 1993; 18:894-901. [DOI: 10.1097/ 00007632-199306000-00014]. 